\title{
Identification in silico of putative damage responsive elements (DRE) in promoter regions of the yeast genome
}

\author{
Walkiria Luckwu de Santana Silva ${ }^{1}$, Andre Ricardo de Oliveira Cavalcanti ${ }^{2}$, Katia Silva Guimarães \\ and Marcos Antonio de Morais Jr. ${ }^{3 *}$ \\ ${ }^{1}$ Universidade Federal de Pernambuco, Centro de Informática, Laboratório de Bioinformática, \\ Recife, PE, Brazil. \\ ${ }^{2}$ Universidade Federal de Pernambuco, Centro de Ciências Exatas e da Natureza, \\ Departamento de Química Fundamental, Recife, PE, Brazil. \\ ${ }^{3}$ Universidade Federal de Pernambuco, Centro de Ciências Biológicas, Departamento de Genética, \\ Recife, PE, Brasil.
}

\begin{abstract}
We report an in silico analysis to identify nucleotide sequence motifs in DNA repair genes that may define a binding site for regulatory proteins during the induction of those genes by mutagens. The damage responsive elements (DRE) weight matrix generated in this analysis was used to search for homologous sequences in the promoter region of all genes, including putative gene and hypothetical open reading frames (ORFs), in the Saccharomyces Genome Data Base (SGD). The results demonstrated that over one third of the yeast genes in the database presented at least one 15 -bp sequence in their promoter region with $85 \%$ or more of similarity to the DRE consensus sequence. The presence of the DRE sequence in the promoter region of regulatory genes and its high similarity to other well reported DNA binding sites points to its involvement in the general regulation of not only DNA repair genes but yeast genes in general.
\end{abstract}

Key words: DNA binding site, DNA repair, gene promoter, gene regulation, Transfac, weight matrix.

Received: September 24, 2004; Accepted: April 12, 2005.

\section{Introduction}

Mutagenic agents that damage DNA can result in increased transcription of a variety of Saccharomyces cerevisiae genes, including DNA repair genes such as the RAD2, RAD7, RAD18, RAD23, RAD51, RAD54, PHR1 and $M A G 1$ as well as genes involved in DNA metabolism and protein modification such as genes RAD6, RNR1, RNR2, RNR3, CDC9, POL1 and UBI4 (Friedberg, 1991). Moreover, four damage inducible (DIN) and six DNA damage responsive (DDR) genes have so far been identified (McClanahan et al., 1984; Ruby and Szostak, 1985). The induction of these genes is dependent on the presence of a set of cis-regulatory sequences in their promoter region, as has been shown by detailed studies of the RAD2 and $R N R 2$ gene promoters (Friedberg, 1991). The promoter region of the RAD2 gene contains two upstream activation sequence (UAS) elements known as damage responsive elements 1

Send correspondence to Marcos Antonio de Morais Jr. Universidade Federal de Pernambuco, Centro de Ciências Biológicas, Departamento de Genética, Av. Moraes Rego s/n, 50732-970 Recife, PE, Brazil. E-mail: morais@lika.ufpe.br.
(DRE1) and 2 (DRE2), essential for DNA-damage induced expression (Siede and Friedberg, 1992), while the RNR2 gene promoter contains three UAS elements (Elledge and Davis, 1989).

Lowndes and Murguia (2000) have schematically described a working model for checkpoint gene regulation in response to different types of DNA damage. In brief, the presence of pre-replicative bulk-lesions or double-strand breaks generated by exposure to mutagenic agents activates parallel upstream sensor mechanisms (UAS elements or upstream repressor sequence (URS) elements) by means of effector proteins that use modification mechanisms such as phosphorylation to activate specific DNA binding proteins that bind to target genes in the UAS or URS elements and arrest both transcription and the cell cycle. Therefore, cell cycle and some metabolic genes are repressed, while DNA repair, DNA metabolism and other metabolic genes are induced. Recently, microarray analysis has been employed to survey the whole $S$. cerevisiae genome in order to form a complete picture of cellular responsiveness to DNA injuries (Jelinsky et al., 2000; Gasch et al., 2001), although it 
still seems that the search for such inducible genes is far from complete.

The SNM1/PSO2 (henceforth called the SNM1 gene) gene belongs to the excision repair pathway (RAD3 pathway) and its product is involved in the repair of interstrand DNA cross-links caused by bifunctional mutagens (Henriques and Brendel, 1990). The SNM1 gene can be induced by cross-linking agents or ultraviolet light (Wolters et al., 1996), serial deletions in the SNM1 gene promoter having showed that a 15-bp sequence homologous to the RAD2 gene and the DRE2 element is essential for $S N M 1$ induction (Wolters et al., 1996). Sequences similar to DRE2 have been found in other genes involved in DNA repair and nucleotide synthesis (Siede and Friedberg, 1992). Since SNM1 gene expression seems to be tightly controlled in yeasts by the presence of DNA lesions, it may offer a good platform to study the DNA repair regulatory circuitry that can be predicted by functional genomics and computational tools. Similarly, deletion of the DRE-like element present at the MAGl gene promoter decreased the level of mutagen-induced gene expression five times (Xiao et al., 1993 ) in a manner similar to that seen for the SNM1 gene (Wolters et al., 1996).

During the in silico study reported in this paper we carried out computational analysis of the promoter region of yeast genes to identify base sequence patterns that could be targeted by activator or repressor proteins in response to DNA damage. We used the DRE1 and DRE2 sequences found in some well-known DNA repair genes such as $R A D 2$ and $S N M 1$ to identify DRE-like sequences in a variety of related and unrelated DNA repair genes.

\section{Materials and Methods}

\section{Matrix sequence preparation}

The DRE-like sequences in the promoter region of the SNM1, RAD2, PHR1, RAD18, RNR3, RAD23 and RAD7 genes have been described as essential for the expression of these genes (Wolters et al., 1996). We submitted these sequences to multiple alignments using the MegAlign tool of the DNAStar software package (DNAStar Inc., USA) to generate a consensus sequence containing $15 \mathrm{bp}$. In parallel, a set of sequences containing the $-1000 \mathrm{bp}$ upstream region of 13 yeast genes described as related to repair in the Saccharomyces Genome Database (SGD) (www. yeastgenome.org) was selected after pairwise alignment of each sequence with the 15 bp consensus generated by us. The SGD set and the consensus sequence were inputted into the Clustal-W program (http://clustalw.genome.ad.jp/) using the default parameters, yielding an alignment which contained several $15 \mathrm{bp}$ sequences which were similar to the $15 \mathrm{bp}$ consensus sequence. The ten highest scored were chosen to produce a new set with the seven original sequences. This new set was then used to generate a weight matrix by using the genome exploring and modeling soft- ware (GEMS) launcher (www.genomatix.de/). The matrix generated was first checked against the whole yeast genome and produced a random expectation of 0.12 matches per 1000 nucleotides. The matrix was also used to scan the $-500 \mathrm{bp}$ upstream region of the yeast genes by using the default conditions (core similarity of 0.9 ) of the MatInspector Professional Program (Quandt et al., 1995; Wingender et al., 2000). This program contains the Transcription Factor Database (TRANSFAC) that allows the identification of the query matrix by comparing to those deposited in the database. The sequences resulting from this search being re-analyzed to estimate the degree of conservation by increasing the core similarity to 0.95 and 1.00 .

\section{Gene annotation and DNA binding motifs analysis}

The genes matching the matrix sequence were first grouped according to their metabolic families by using the MIPS (http://www.mips.biochem.mpg.de/) and YPD (http://www.proteome.com/database/YPD). The gene clusters and DNA binding sequences used were those available on-line at http://arep.med.harvard.edu/network_discovery/ (Tavazoie et al., 1999) and http://cgsigma.cshl.org/jian/ (Zhu and Zhang, 1999). The microarray data from mutagen-treated cells was taken from http://www.hsph. harvard.edu/geneexpression/ (Jelinsky et al., 2000) and http://www-genome.stanford.edu/Mec1/ (Gasch et al., 2001).

\section{Results}

Identification of DRE-matrix element in yeast DNA repair genes

The sequence of the DRE-like sequence was 5'-GNRRAKGNATTGAAA-3' (The bold-face letters N, $\mathrm{R}, \mathrm{R}, \mathrm{K}$ and $\mathrm{N}$ correspond to five ambiguous nucleotide positions) as established by the alignment of the DNA repair genes described by Wolters et al. (1996) and 13 other DNA repair genes collected from SGD. Unless otherwise indicated, references to DRE-like sequences refer to sequences conforming to this sequence henceforth. The nucleotide codes used were according to the International Union of Pure and Applied Chemistry (IUPAC). The consensus index for each nucleotide position is shown in Figure 1.

When we scanned the -500 bp sequence of the yeast genome we found many genes containing sequences which were similar to the DRE-like consensus sequence with complete conservation in the core TGAAA sequence at the 3 ' end (Table 1). Other nucleotides also seem to be conserved, includes the nucleotide $\mathrm{G}$ at position $1, \mathrm{~A}$ at position 5, G at position 7 and the dinucleotide AT just before the core. All genes identified in Table 1 were induced by at least one mutagen according to microarray data produced by Jelinsky et al. (2000), although the induction level and the nature of the mutagen were variable. 


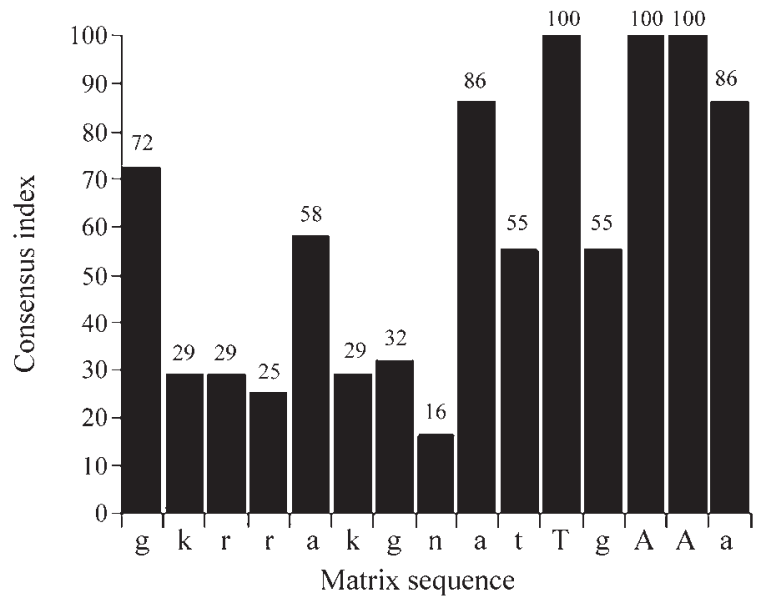

Figure 1 - Matrix sequence output by MatDefine from GEMS Launcher suite v3.6 using damage repair elements (DRE) identified from yeast DNA repair genes. Capital letters in the DNA sequence represent nucleotide positions with high consensus index score ( $\mathrm{Ci}$-value $>60)$ as indicated by MatInspector. Ci-values are shown above the gray bars.

Our SGD search for homologous sequences in the -500 bp promoter region of yeast genes yielded a total of 1645 matches with at least $85 \%$ matrix similarity and $100 \%$ similarity to the core TGAAA. In the rest of this paper we will use the term 'gene' to refer not only to both identified and putative genes but also in some cases even to hypothetical ORFs described on the SGD web site. The MatInspector result suggested that this element might be widespread in the promoter regions of the yeast genome, these regions accounting for a third of the total genes described in the SGD.

We also found two matches in the promoter regions of the ORFs YER041w (YEN1 gene) and YEL018w
(Table 1), with the last ORF presenting two DRE-like consensus sequences in its promoter region. Both ORFs have been described in the Yeast genome Database as putative DNA repair genes, which were induced by treatment with methyl methane sulfoxide (MMS) and with 4-nitroquinoline 1-oxide (4-NQO).

When we increased the matrix similarity threshold to $95 \%$ the number of matches decreased substantially to 15 a group of genes (Table 2), with the SNM1 gene being the only gene in this group involved in some type of DNA metabolism and six (including the glutamate 5-kinase encoding PRO1 gene containing the complete DRE-like consensus in the promoter region) were not induced by any mutagen (Table 2). These results indicate that despite its function in the induction of the SNM1 gene the DRE-like sequence may act as a regulatory element for other genes.

Additionally, the SNZ1 gene was the only match containing four DRE-like consensus sequences and it was also described by Jelinsky et al. (2000) as being very susceptible to induction by mutagens with an induction factor of about 82 after treatment with MMS. This gene is induced in response to nitrogen limitation and growth arrest, and its protein product is part of the glutamine amidotransferase complex together with Sno1 protein (Dong et al., 2004). We found another 20 matches containing three DRE-like consensus sequences presenting from $85 \%$ to $95 \%$ matrix similarity, none of which were was directly involved in DNA repair. In our analysis, three ORFs (YLR060W, phenylalanyl-tRNA synthetase; YLR224W, hypothetically a protein; and YLR059C, putative 3'-5' exonuclease) containing three DRE-like consensus sequences were not known to be induced by any mutagen yet tested, so there was no exact correlation between the presence or the num-

Table 1 - Computational analysis of DNA repairs genes from S. cerevisiae identified by MatInspector algorithm containing DRE-matrix elements in their promoters.

\begin{tabular}{|c|c|c|c|c|c|c|}
\hline Gene/SGD access & Biological function $^{\mathrm{a}}$ & Upstream position $^{\mathrm{b}}$ & DNA strand ${ }^{b}$ & Matriz similarity $^{\mathrm{c}}$ & Sequence $\left(5^{\prime}-3^{\prime}\right)$ & Induction factor \\
\hline RAD50/YNL250W & Strand-break repair protein & $213-227$ & $(-)$ & 0.852 & GGCAAAGC CGTGAAA & 2.5 (BCNU) \\
\hline$P S O 2 / Y M R 137 \mathrm{C}$ & ICL repair protein & 384-398 & $(+)$ & 0.957 & GGAAACGG ACTGAAA & $3.4(8-\mathrm{MOP})^{\mathrm{e}}$ \\
\hline$M G T 1 / Y D L 200 C$ & $\mathrm{O}^{6}$-Methyltransferase & $182-196$ & $(-)$ & 0.862 & TCAGATGT AATGAAA & 3.3 (MMS) \\
\hline$R A D 16 / \mathrm{YBR} 114 \mathrm{~W}$ & NER protein & $482-496$ & $(+)$ & 0.906 & GTGTACCA ACTGAAA & $3.4(\mathrm{t}-\mathrm{BuOOH})$ \\
\hline RAD18/YCR066W & Error-prone repair protein & $22-36$ & $(-)$ & 0.924 & GAAAAGAA AATGAAA & 2.9 (MMS) \\
\hline RAD23/YEL037C & NER protein & $207-221$ & $(+)$ & 0.907 & GTGGCGAA ATTGAAA & 2.5 (BCNU) \\
\hline YEN1/YER041W & Weak similarity to $\operatorname{Rad} 2 p$ & $\begin{array}{c}93-107 \\
432-446\end{array}$ & $\begin{array}{l}(-) \\
(+)\end{array}$ & $\begin{array}{l}0.872 \\
0.905\end{array}$ & $\begin{array}{l}\text { TCAGAGGT AATGAAA } \\
\text { GTCCATCC AATGAAA }\end{array}$ & 3.3 (MMS) \\
\hline EAF5/YEL018W & Weak similarity to Rad50p & $39-53$ & $(+)$ & 0.850 & GAGGATTG TTTGAAA & $2.5(4 \mathrm{NQO})$ \\
\hline Matrix ${ }^{f}$ & & & & & GKRRAKGN ATTGAAA & \\
\hline
\end{tabular}

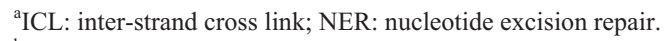

${ }^{\mathrm{b}}$ Upstream nucleotide position relative to +1 and Watson $(+)$ or Crick (-) strands relative to SGD.

${ }^{c}$ DRE sequence similarity relative to the matrix.

${ }^{\mathrm{d}}$ Microarray data published by Jelinsky et al. (2000), considering the highest induction value with a specific mutagen in brackets. Abbreviations: MMS (methyl metanosulfonate), BCNU (1.3-bis-2-chloroethyl-1-nitrosourea), t-BuOOH (tert-buthyl hydroperoxide), 4-NQO (4-nitroquinoline 1-oxide) and 8-MOP (8-methoxypsoralen).

${ }^{\mathrm{e}}$ Data from Wolters et al. . (1996) using SNM1-lacZ fusion.

${ }^{f}$ Highly conserved $(80 \%)$ nucleotide sequences are in bold. Ambiguous codes are according to IUPAC: N (any), R (A or G) and K (G or T). 
Table 2 - List of the yeast genes showing 95\% or more sequence similarity in their upstream sequences to DRE-matrix ${ }^{\mathrm{a}}$.

\begin{tabular}{|c|c|c|c|c|c|c|}
\hline Gene/SGD access & Biological function & $\begin{array}{l}\text { Upstream } \\
\text { position }\end{array}$ & $\begin{array}{l}\text { DNA } \\
\text { strand }\end{array}$ & $\begin{array}{l}\text { Matrix } \\
\text { similarity }\end{array}$ & Sequence (5'-3') & $\begin{array}{l}\text { Induction } \\
\text { factor }\end{array}$ \\
\hline PSO2/YMR137C & ICL repair protein & $384-398$ & $(+)$ & 0.957 & GGAAACGG ACTGAAA & 3.4 (8-MOP) \\
\hline$P A C 11 / Y D R 488 C$ & Required in the absence of Cin8p & $479-493$ & $(+)$ & 0.952 & GAAGAAGG ATTGAAA & 5.5 (4-NQO) \\
\hline PIN4/YBL051C & Similar Z66568Cp of S.pombe & $109-123$ & $(-)$ & 0.958 & GTAGAGTT ATTGAAA & not induced \\
\hline PRE3/YJL001W & Endopeptidase multicatalytic complex subunit & $396-410$ & $(+)$ & 0.967 & GGAAAAGC ATTGAAA & $4.9(\mathrm{t}-\mathrm{BuOOH})$ \\
\hline RTS1/YOR014W & Phosphatase A regulatory subunit & $318-332$ & $(-)$ & 0.962 & GGGAAGGA AATGAAA & $2.5(\mathrm{t}-\mathrm{BuOOH})$ \\
\hline YLR282C & Questionable ORF & $446-460$ & $(-)$ & 0.962 & GGCAATGG ATTGAAA & not induced \\
\hline OST1/YJL002C & Oligosacaryltransferase alfa subunit & $80-94$ & $(-)$ & 0.967 & GGAAAAGC ATTGAAA & not induced \\
\hline$N I F 3 / Y G L 221 \mathrm{C}$ & Ngg1p-interacting factor 3 & $399-413$ & $(-)$ & 0.968 & GTGAAAGA ATTGAAA & $2.0(4-\mathrm{NQO})$ \\
\hline PUF6/YDR496C & Similar to hypothetical human protein & $141-155$ & $(+)$ & 0.962 & GTTCATGA ATTGAAA & not induced \\
\hline PEX22/YAL055W & Hypothetical protein & $235-249$ & $(-)$ & 0.970 & GTGAAAGC ATTGAAA & $2.9(\mathrm{t}-\mathrm{BuOOH})$ \\
\hline$M U B 1 / \mathrm{YMR} 100 \mathrm{~W}$ & Hypothetical protein & $393-407$ & $(-)$ & 0.976 & GGAAATGA ATTGAAA & $5.5(4-\mathrm{NQO})$ \\
\hline$C L P 1 / \mathrm{YOR} 250 \mathrm{C}$ & $\begin{array}{l}\text { Similarity to SPAC } 22 \mathrm{H} 10.05 \text { c protein of } \\
\text { S.pombe }\end{array}$ & $59-73$ & $(+)$ & 0.974 & GAAAAGGC ATTGAAA & 3.5 (MMS) \\
\hline DRS2/YAL026C & $\begin{array}{l}\text { Type-P amino-phospholipid-ATPase } \\
\text { transmembrane }\end{array}$ & $92-106$ & $(-)$ & 0.974 & GTAAAAGA ATTGAAA & not induced \\
\hline$C F T 1 / Y D R 301 \mathrm{~W}$ & Pre-mRNA 3'-terminal processing factor & $126-140$ & $(-)$ & 0.995 & GTAAAGGA ATTGAAA & 4.9 (4-NQO) \\
\hline$P R O 1 / \mathrm{YDR} 300 \mathrm{C}$ & Glutamate 5-kinase & $301-315$ & $(+)$ & 0.995 & GTAAAGGA ATTGAAA & not induced \\
\hline
\end{tabular}

${ }^{\mathrm{a}}$ Descriptions, symbols and abbreviations are as described in Table 1.

ber of DRE-like consensus sequences and the ability of a gene to be induced by a mutagen.

We were also able to identify 19 transcription factor-encoding genes containing in their promoter regions upstream sequences which were more than $90 \%$ similar to the DRE-like consensus element, 15 of these genes being inducible by treatments which damage DNA (Table 3). Ten of the 15 mutagen-inducible genes encode subunits of the so-called basal transcription complex, which either binds to the TATA box or correctly localize the RNA polymerase complex at the initiation site during initiation of transcription. Additionally, DRE-like consensus sequences were identified at the promoter region of genes encoding specific transcription factors, such as Gal4p, Leu3p and Gcr3p (Table 3). Therefore, the presence of DRE-like consensus sequences in the promoter region of regulatory genes may

Table 3 - Yeast transcription factor-encoding genes identified by MatInspector for the presence of a DRE-matrix motif in their -500 bp promoter sequence ${ }^{\mathrm{a}}$.

\begin{tabular}{|c|c|c|c|c|c|c|}
\hline Gene/SGD access & Biological function & $\begin{array}{l}\text { Upstream } \\
\text { position }\end{array}$ & $\begin{array}{l}\text { DNA } \\
\text { strand }\end{array}$ & $\begin{array}{l}\text { Matrix } \\
\text { similarity }\end{array}$ & Sequence (5'-3') & $\begin{array}{l}\text { Induction } \\
\text { factor }\end{array}$ \\
\hline DST1/YGL043W & TFIIS elongation factor & $\begin{array}{c}75-89 \\
358-372 \\
415-429\end{array}$ & $\begin{array}{l}(-) \\
(-) \\
(+)\end{array}$ & $\begin{array}{l}0.86 \\
0.87 \\
0.92\end{array}$ & $\begin{array}{l}\text { ATCAATAC ATTGAAA } \\
\text { GGGTAAGA GTTGAAA } \\
\text { GACTACGT ATTGAAA }\end{array}$ & 3.4 (MMS) \\
\hline GAL4/YPL248C & Galactose induction factor & $\begin{array}{l}209-223 \\
279-293\end{array}$ & $\begin{array}{l}(-) \\
(-)\end{array}$ & $\begin{array}{l}0.87 \\
0.88\end{array}$ & $\begin{array}{l}\text { GCGGACGT TTTGAAA } \\
\text { GTAAATAC TTTGAAA }\end{array}$ & not induced \\
\hline$G C R 3 / \mathrm{YMR} 125 \mathrm{~W}$ & Glycolytic genes induction factor & $457-471$ & $(-)$ & 089 & GTAATTTG AATGAAA & $2.7(4-\mathrm{NQO})$ \\
\hline LEU3/YLR451W & $\begin{array}{l}\text { Branched-chain amino acids genes induction } \\
\text { factor }\end{array}$ & $342-356$ & $(+)$ & 0.89 & GAGCAAAA AATGAAA & 4.0 (MMS) \\
\hline$M B P 1 / Y D L 056 \mathrm{~W}$ & MBF complex subunit & $330-344$ & $(+)$ & 0.86 & GATGAAAA AATGAAA & 2.0 (MMS) \\
\hline$M G A 1 / Y G R 249 \mathrm{~W}$ & Similar to heat shock factor & $153-167$ & $(-)$ & 089 & GGTCAACA ACTGAAA & not induced \\
\hline$R E B 1 / \mathrm{YBR} 049 \mathrm{C}$ & Transcription factor & $\begin{array}{l}150-164 \\
151-165\end{array}$ & $\begin{array}{l}(-) \\
(+)\end{array}$ & $\begin{array}{l}0.89 \\
0.86\end{array}$ & $\begin{array}{l}\text { TTCAATGT ATTGAAA } \\
\text { TTCAATAC ATTGAAA }\end{array}$ & $2.6(\mathrm{MNNG})$ \\
\hline$R F A 2 / \mathrm{YNL} 312 \mathrm{~W}$ & $36 \mathrm{kDa}$ DNA replication factor & 180-194 & $(-)$ & 0.85 & GTAGAATC TCTGAAA & 5.1 (MMS) \\
\hline$R R N 10 / \mathrm{YBL} 025 \mathrm{~W}$ & $\begin{array}{l}\text { RNA polymerase I-specific initiation tran- } \\
\text { scription factor }\end{array}$ & $373-387$ & $(+)$ & 0.86 & GCGAATGT CATGAAA & 3.5 (MMS) \\
\hline$R R N 6 / \mathrm{YBL} 014 \mathrm{C}$ & $\begin{array}{l}\text { RNA polymerase I-specific initiation tran- } \\
\text { scription factor }\end{array}$ & $\begin{array}{c}63-77 \\
210-224\end{array}$ & $\begin{array}{c}(+) \\
(-)\end{array}$ & $\begin{array}{l}0.89 \\
0.89\end{array}$ & $\begin{array}{l}\text { GAGAAATT ACTGAAA } \\
\text { GTGAGAAG ATTGAAA }\end{array}$ & $2.3(4-\mathrm{NQO})$ \\
\hline$R R N 7 / \mathrm{YJL} 025 \mathrm{~W}$ & $\begin{array}{l}\text { RNA polymerase I-specific initiation tran- } \\
\text { scription factor }\end{array}$ & $346-360$ & $(+)$ & 0.87 & TTAAAAAA ATTGAAA & $2.6(\mathrm{BCNU})$ \\
\hline SKN7/YHR206W & Similar to heat shock factor & $207-221$ & $(+)$ & 0.89 & GTGACAAG ATTGAAA & not induced \\
\hline
\end{tabular}


Table 3 (cont.)

\begin{tabular}{|c|c|c|c|c|c|c|}
\hline Gene/SGD access & Biological function & $\begin{array}{l}\text { Upstream } \\
\text { position }\end{array}$ & $\begin{array}{l}\text { DNA } \\
\text { strand }\end{array}$ & $\begin{array}{c}\text { Matrix } \\
\text { similarity }\end{array}$ & Sequence $\left(5^{\prime}-3^{\prime}\right)$ & $\begin{array}{l}\text { Induction } \\
\text { factor }\end{array}$ \\
\hline TAF40/YML015C & TBP-associated $40 \mathrm{kDa}$ TFIID subunit & $407-421$ & $(+)$ & 0.88 & TGAAAGAA ATTGAAA & 4.0 (MMS) \\
\hline$T A F 61 / Y D R 145 \mathrm{~W}$ & TBP-associated $61 \mathrm{kDa}$ TFIID subunit & $34-48$ & $(+)$ & 0.87 & AATAAGGT ATTGAAA & $5.2(4-\mathrm{NQO})$ \\
\hline$T A F 67 / Y M R 227 \mathrm{C}$ & TBP-associated $67 \mathrm{kDa}$ TFIID subunit & $114-128$ & $(-)$ & 0.86 & CCAGAAGA ATTGAAA & 8.8 (MMS) \\
\hline$T A F 90 / \mathrm{YBR} 198 \mathrm{C}$ & TBP-associated $90 \mathrm{kDa}$ TFIID subunit & $241-255$ & $(-)$ & 0.86 & CTGCATGT AGTGAAA & 3.2 (MMS) \\
\hline$T F B 1 / \mathrm{YDR} 311 \mathrm{~W}$ & TFIIH subunit & $256-270$ & $(+)$ & 0.86 & GGGAAAGA TATGAAA & $2.6(4-\mathrm{NQO})$ \\
\hline$T F C 1 / \mathrm{YBR} 123 \mathrm{C}$ & TFIIIC subunit & $401-415$ & $(+)$ & 0.88 & AGACAGGA ACTGAAA & 3.2 (MMS) \\
\hline$T F C 2 / \mathrm{YPR} 186 \mathrm{C}$ & TFIIIA subunit & $383-397$ & $(-)$ & 0.86 & GATATTTA ATTGAAA & not induced \\
\hline
\end{tabular}

${ }^{\text {a}}$ Descriptions, symbols and abbreviations are as described in Table 1.

support the idea of the complex inter-connection of metabolic networks.

\section{Homology between the DRE-like consensus sequence and known yeast DNA binding sites}

Searching for homologous sequences was performed in the Saccharomyces cerevisiae Promoter Database (SCPD) using the consensus sequence and admitting six possible mismatches corresponding to the five ambiguous nucleotide positions in the matrix GNRRAKGNAT TGAAA (in bold) plus one mismatch at any of the other positions. A total of 16 transcriptional factor-binding sites were identified during our analysis (Table 4). The heat shock element (HSE) controls the stress response of several yeast genes encoding heat shock proteins by binding the heat shock transcription factor (HSF) described by Sakurai and Fukasawa (2001). All HSP genes were induced by mutagens with the exception of the HSE-containing CUP1 gene that was mutagen-repressed (Jelinsky et al., 2000).

High homology was also observed between the DRElike consensus sequence and the stress response element (STRE) present at the promoter region of the DDR2 gene (Table 4). This gene is induced by a variety of mutagens as well as by heat shock but the function of its protein product is still unknown (Treger et al., 1998). A previous computer-generated pattern also identified a STRE motif for DDR48 gene (Treger et al., 1998), because of which we also performed sequence alignment of the $D D R 48$ gene promoter and identified the presence of the homologous element 5'GGCCAGCACCGGAAA-' (conserved positions in bold) at position -318 to -304 at the Crick strand. The third member of this group, the polyubiquitin encoding gene UBI4 is induced in response to a variety of environmental stresses such as mutagens and heat shock due to the presence of both HSE and STRE sequences in its promoter region (Simon et al., 1998). Our pairwise alignment analysis with the DRE sequence identified the sequence 5'-TAAAAAAGATTG AAC-3' (conserved nucleotides in bold) at positions -301 to -315 in the promoter region of the STE12 gene encoding a transcription factor involved in pheromone and pseudohyphal growth signal transduction pathways.
Table 4 - Motifs in the yeast genome homologous to the DRE sequence.

\begin{tabular}{|c|c|c|c|}
\hline $\begin{array}{l}\text { Transcription } \\
\text { factor }\end{array}$ & $\begin{array}{l}\text { Binding } \\
\text { motif }\end{array}$ & Sequence $\left(5^{\prime}-3^{\prime}\right)$ & Cell metabolism \\
\hline- & DRE & GKRRAKGN ATTGAAA & \\
\hline Hsfp & HSE & GGAACGTT CTGGAAA & Stress response \\
\hline $\operatorname{Msn} 2 / 4 p$ & STRE & ATAAGGGG TGAGAAA & Cell death and aging \\
\hline Ime1p & IRE & GGGAAAGG ATCAAAG & $\begin{array}{l}\text { Pre-meiotic DNA } \\
\text { synthesis }\end{array}$ \\
\hline Ino2p/Ino4p & - & CATGTGAAAAATGTGAAA & $\begin{array}{l}\text { Phospholipid } \\
\text { biosynthesis }\end{array}$ \\
\hline Dal82p & - & GAAAAGCA AACGCAA & Purine biosynthesis \\
\hline Abflp & - & GTAAGGCG CTATCAA & DNA replication \\
\hline Adrlp & - & GTGACAGA ATTGGAG & $\begin{array}{l}\text { Cell aging and fer- } \\
\text { mentation }\end{array}$ \\
\hline $\operatorname{Mot} 3 p$ & - & GTAATAGG GATCAAT & $\begin{array}{l}\text { Mating and transpo- } \\
\text { sition }\end{array}$ \\
\hline Rap1p & - & CCATACTT TTTGAAA & $\begin{array}{l}\text { Chromatin mainte- } \\
\text { nance }\end{array}$ \\
\hline Cbflp & - & AATGATTC ATTGAAA & $\begin{array}{l}\text { Chromosome segre- } \\
\text { gation }\end{array}$ \\
\hline- & $\mathrm{MCB}$ & GGGTAACG CCTGAAA & Cell cycle control \\
\hline- & $\mathrm{ECB}$ & GGAAACGT AATGAAA & Cell cycle control \\
\hline- & $\mathrm{SCB}$ & -TGTAA ATTGAAA & Cell cycle control \\
\hline- & M13 & ACCGAACA AATGAAA & n.d. \\
\hline- & M27 & GAAAGAAA TTTGAAA & n.d. \\
\hline- & M3a & TAAAGAAA ATTGAAA & n.d. \\
\hline
\end{tabular}

n.d.: not defined within a recognizable pathway by Tavazoie et al. (1999).

\section{Discussion}

Our homology similarity-based searches in the promoter regions of the whole yeast genome using a consensus sequence based on the 5'-GNRRAKGNATTGAAA-3' DRE-like consensus led to some intriguing results. Firstly, our data shows that not all DNA repair genes that contain the DRE-like consensus sequence analyzed in this work were induced by the mutagens tested by Jelinsky et al. (2000), although, of course, induction by other mutagens not yet tested cannot be ruled out. Microarray analysis also revealed interesting data in relation to gene regulation in that of the 12 genes in the microarray profile with signifi- 
cant mutagen induction only $R N R 3$ is involved in DNA metabolism (Jelinsky et al., 2000). Ren et al. (2000) have demonstrated that the expression of the FUR4 gene is increased by the presence of galactose despite the fact that its promoter region does not contain any Gal4p consensus sequence binding site, although yet other yeast genes exist which contain the Gal4p binding site but are not galactoseinducible. Therefore, we cannot discard the possibility that our 5'-GNRRAKGNATTGAAA-3' DRE-like sequence is involved in some kind of gene expression regulation. This suggests that the simple presence of a DRE-like sequence alone may not be a good enough indicator for gene induction by DNA-damage agents, although its presence is essential for induction of the SNM1/PSO2 (Wolters et al., 1996) and MAG1 (Xiao et al., 1993) genes. Ren et al. (2000) and Iyer et al. (2001) have indicated the need for additional empirical data and combined, and perhaps improved, search algorithms in order for investigators to accurately predict genuine binding sites.

Tavazoie et al. (1999) have proposed transcriptional regulatory networks based on clustering yeast genes according to the presence of putative cis-regulatory sequences in their promoter regions, these authors showing that the STRE factor is more frequent in genes belonging to cluster 8 which is rich in genes related to carbohydrate and tricarboxylic acid (TCA) metabolism. Intriguingly, the only genes in our analysis belonging to Tavazoie's cluster 8 were $R A D 14$ and $U B I 4$ and no other stress or DNA damage responsive genes. Genes involved in DNA synthesis and replication, cell cycle control and mitosis, recombination and DNA repair were allocated to Tavazoie's cluster 2, while genes responsive to stress and involved in cell rescue, defense and cell death were allocated to cluster 5 (Tavazoie et al., 1999). Gene cluster 2 is characterized by the presence of MCB and SCB sequence motifs (Table 4), and, to a lesser extent, the M13 motif, which were all also recognized as homologous to our DRE-like sequence (Table 4). The presence of MCB binding sites was reported to confer irradiation-replication specific regulation on many DNA repair genes (Mercier et al., 2001). Cluster 5 genes, to which DNA repair genes $M A G 1$ and RAD10 belong, also contain mainly the M13 motif (Tavazoie et al., 1999). This motif contains the pentanucleotide TGAAA that is recognized by the Adr1p transcriptional factor. The homology we found between M13 and our DRE-like sequence (Table 4) suggests that the 5'-GNRRAKGNATTGAAA-3' DRE sequence can be also recognized by a transcription factor. Similarly, Ettwiller et al. (2003) combined information from metabolic networks with genome information to predict cis-regulatory sequences in yeast promoters, their analysis producing 42 motifs with motif 19 showing high similarity to our DRE-like sequence and since motif 19 is not a recognized yeast transcription factor binding motif it is possible that it may represent a new regulatory motif.
In an attempt to describe a new method for identification of regulatory sequences, Harrison and DeLisi (2001) identified the consensus sequence AWGAAA as a target for binding of the Ste12 transcription factor by using the anchor motif generation method. The AWGAAA motif is similar to those previously described in TRANSFAC (ATGAAC) and the SCPD (ATGAAA) databases, these sequences being identical to the core sequence (ATGAAA) of our 5'-GNRRAKGNATTGAAA-3' DRE-like sequence. The homology found between our DRE-like sequence and the previously identified regulatory motifs, either experimentally or by in silico analysis, suggests that these sequences belong to a family of regulatory sequences participating in the general mechanism of gene regulation. Further experimental data should confirm this hypothesis.

\section{Acknowledgments}

The authors are grateful to Dr. K. Quandt (Genomatix, Germany) for permission to use GEMS Launcher professional to prepare the DRE-matrix.

\section{References}

Dong YX, Sueda S, Nikawa J and Kondo H (2004) Characterization of the products of the genes SNO1 and SNZ1 involved in pyridoxine synthesis in Saccharomyces cerevisiae. Eur J Biochem 271:745-52.

Elledge SJ and Davis RW (1989) Identification of the DNA damage responsive element of $R N R 2$ and evidence that four distinct cellular factors bind it. Mol Cell Biol 9:5373-5386.

Errede B and Ammerer G (1989) STE12, a protein involved in cell-type-specific transcription and signal transduction in yeast, is part of protein-DNA complexes. Genes Develop 3:1349-1361.

Ettwiller LM, Rung J and Birney E (2003) Discovering novel cis-regulatory motifs using regulatory networks. Genome Res 13:883-895.

Friedberg EC (1991) Yeast genes involved in DNA repair process: New looks on old faces. Mol Microbiol 5:2303-2310.

Gasch AP, Huang M, Metzner S, Botstein D, Elledge SJ and Brown PO (2001) Genomic expression responses to DNAdamage agents and the regulatory role of the yeast ATR homolog Mec1p. Mol Cell Biol 12:2987-3003.

Harrison H and DeLisi C (2001) Condition specific transcription factor binding site characterization in Saccharomyces cerevisiae. Bioinformatics 18:1289-1296.

Henriques JAP and Brendel M (1990) The role of PSO and SNM genes in DNA repair of the yeast Saccharomyces cerevisiae. Curr Genet 18:387-393.

Hughes JD, Estep PW, Tavazoie S and Church GM (2000) Computational identification of cis-regulatory elements associated with groups of functionally related genes in Saccharomyces cerevisiae. J Mol Biol 296:1205-1214.

Iyer VR, Horak CE, Scafe CS, Botstein D, Snyder M and Brown PO (2001) Genomic binding sites of the yeast cell-cycle transcription factors SBF and MBF. Nature 409:533-538.

Jelinsky S, Estep P, Church G and Samson L (2000) Regulatory networks revealed by transcriptional profiling of damaged 
Saccharomyces cerevisiae cells: RPN4 links base excision repair with proteasomes. Mol Cell Biol 20:8157-8167.

Kiser GL and Weinert TA (1996) Distinct roles of yeast $M E C$ and $R A D$ checkpoint genes in transcriptional induction after DNA damage and implications for function. Mol Cell Biol 7:703-718.

Lowndes NF and Murguia JR (2000) Sensing and responding to DNA damage. Curr Opin Genet Dev 10:17-25.

McClanahan T and McEntee K (1984) Specific transcripts are elevated in Saccharomyces cerevisiae in response to DNA damage. Mol Cell Biol 4:2356-2363.

Mercier G, Denis Y, Marc P, Picard L and Dutriex M (2001) Transcriptional induction of repair genes during slowing of replication in irradiated Saccharomyces cerevisiae. Mut Res 487:157-172.

Quandt K, Frech K, Karas H, Wingender E and Werner T (1995) MatInd and MatInspector: New fast and versatile tools for detection of consensus matches in nucleotide sequence data. Nucl Acids Res 23:4878-4884.

Ren B, Robert F, Wyrick JJ, Aparicio O, Jennings EG, Simon I, Zeitlinger J, Schreiber J, Hannett N, Kanin E, Volkert TL, Wilson CJ, Bell SP and Young RA (2000) Genome-wide location and function of DNA binding proteins. Science 290:2306-2309.

Ruby SW and Szostak JW (1985) Specific Saccharomyces cerevisiae genes are expressed in response to DNAdamaging agents. Mol Cell Biol 5:75-84.

Sakurai H and Fukasawa T (2001) A novel domain of the yeast heat shock factor that regulates its activation function. Biochem Biophys Res Commun 285:696-701.
Siede W and Friedberg EC (1992) Regulation of the yeast RAD2 gene: DNA damage-dependent induction correlates with protein binding to regulatory sequences and their deletion influences survival. Mo Gen Genet 232:247-256.

Simon JR, Treger JM and McEntee K (1998). Multiple independent regulatory pathways control UBI4 expression after heat shock in Saccharomyces cerevisiae. Mol Microbiol 31:823-832.

Tavazoie S, Hughes JD, Campbell MJ, Cho RJ and Church GM (1999) Systematic determination of genetic network architecture. Nat Genet 22:281-285.

Treger JM, Schmitt AP, Simon JR and McEntee K (1998). Transcriptional factor mutations reveal regulatory complexities of heat shock and newly identified stress genes in Saccharomyces cerevisiae. J Biol Chem 273:26875-26879.

Wingender E, Chen X, Hehl R, Karas H, Liebich I, Matys V, Meinhardt T, Prüß M, Reuter I and Schacherer F (2000) TRANSFAC: An integrated system for gene expression regulation. Nucl Acids Res 28:316-319.

Wolter R, Siede W and Brendel M (1996) Regulation of SNM1, an inducible Saccharomyces cerevisiae gene required for repair of DNA cross-links. Mol Gen Genet 250:162-168.

Xiao W, Singh KK, Chen B and Samson L (1993) A common element involved in transcriptional regulation of two DAN alkylation repair genes ( $M A G$ and $M G T 1)$ of Saccharomyces cerevisiae. Mol Cell Biol 13:7213-7221.

Zhu J and Zhang MQ (1999) SCPD: A promoter database of the yeast Saccharomyces cerevisiae. Bioinformatics 15:607611

Associate Editor: Sérgio Olavo Pinto da Costa 